\title{
Trauma and the (Im)Possibility of Representation: Patrick McGrath's Trauma
}

DAVID KERLER

UNIVERSITÄT AUGSBURG

ABSTRACT: The present paper explores the notion of trauma as the epitome of the postmodern crises of representation and communication. Through the example of Patrick McGrath's novel Trauma (2008), the trauma phenomenon will be scrutinized as thematic and aesthetic paradigm of contemporary literature. A close reading of McGrath's novel shall elucidate trauma's paradoxical structure of presence and absence, i.e. its call for articulation and simultaneous representational elusiveness. Special attention will be given to the narrative techniques and stylistic devices the text employs to give (an aesthetic) voice to the unspeakable. Abstracting from the results of these analyses, an aesthetics of the unrepresentable will be elaborated in the final section of the paper.

Keywords: trauma, Patrick McGrath, presence, absence, representation, metanarrative.

RESUMEN: El presente artículo explora el concepto de trauma como epítome de las crisis posmodernas de representación y comunicación. Mediante el análisis detallado de la novela de Patrick McGrath Trauma (2008), se abordará el fenómeno traumático como paradigma temático y estético de la literatura contemporánea. Igualmente, se delineará la estructura paradójica del trauma, expresada a través de la dicotomía presencia/ausencia, es decir, su necesidad de articulación y simultánea naturaleza representacional difusa. Se prestará especial atención a las técnicas narrativas y recursos estilísticos empleados en el texto para dotar de voz (estética) a lo innombrable. La sección final propone las claves para una estética narrativa de la irrepresentabilidad a partir del análisis desarrollado.

Palabras clave: trauma, Patrick McGrath, presencia, ausencia, representación, metanarrativa. 


\section{Introduction: Trauma - the Postmodern Zeitgeist?}

The question of the limits of representation, the breakdown of communication and art's supplementary role in the light of these voids lead right to the phenomenon of trauma and its multi-layered discourses. Looking at recent history, one might argue that trauma is the epitome of the $20^{\text {th }}$ and early $21^{\text {st }}$ century: two devastating World Wars, the Vietnam War, the Iraq War(s), numerous terrorist attacks, which reached their (medial) climax in $9 / 11$, as well as the disturbing images of the Abu Ghraib prison, to name but a few examples. These events not only brought forth myriads of traumatized victims, but they were also increasingly present in the collective perception due to rapid developments in the area of communication media. Although we are living in times highly dominated by media and (visual) representation, trauma, however, eludes the latter. It is rather characterized by a paradoxical presence/absence within the traumatized subject's psyche: on the one hand, the trauma is present in the sense that it hauntingly calls for its articulation; on the other hand, it is absent since it cannot be completely represented/articulated, i.e. no scheme of knowledge or meaningful narrative is able to fully grasp its exceeding singularity (Caruth, 1995: 153; Caruth, 1996: 4-7; Roth, 2011: 77-82; Luckhurst, 2008: 4f.). In the latter sense, Michael S. Roth speaks of the «dilemmas of [particularly narrative] representation» (Roth, 2011: 77), especially in the context of the so-called Historikerstreit and the commemoration of World War II (Roth, 2011: 82-84), and Cathy Caruth rather understands «trauma in terms of its indirect relation to reference» (Caruth, 1996: 7). As Roth (2011: 99f.) further observes, the notion of trauma's paradoxical structure perfectly fits the (post)modern subject's consciousness of fragmentation and estrangement, i.e. «the view that we are not fully present to ourselves and that we represent all our experiences to ourselves in highly mediated forms» (Roth, 2011: 99). ${ }^{1}$ In the light of the aforementioned issues of representation, it is the condition of post-industrial western society which finally exacerbates these uncertainties. Starting with antique myths right through to their replacement by religion(s), philosophies and ideologies, societies all the while constructed their soothing narratives which were quite successful in meaningfully articulating the traumatic horrors of reality. As the influential French philosopher Jean-François Lyotard highlights in La condition postmoderne (1979), however, these so-called grand récits have lost their claim as universal models of explanation these days, thus equally losing their representational and soothing function with regard to

1. Conversely, «[c]ontemporary theory is traumatophilic» (Roth, 2011: 99) and, in addition to it, makes a major contribution to the construction of post-traumatic subjectivity (Luckhurst, 2008: 15). 
traumatic experiences. In short, the notion of trauma proves to be a fundamental paradigm of the (post)modern Zeitgeist, to which the crises of representation and communication converge.

This condition is most notably echoed in a large number of trauma narratives in contemporary literature, such as in Holocaust literature, South African postapartheid fiction, American post-9/11 fiction, or in a huge variety of Spanish (meta-) historical novels that deal with the traumatic experiences of the Spanish Civil War and Francisco Franco's subsequent dictatorship. Within the broad range of noteworthy English novels - including Julian Barnes's A History of the World in 10 1/2 Chapters (1989), Martin Amis's Time's Arrow (1991) and Ian McEwan's highly praised Atonement (2001) - it is especially Patrick McGrath's Trauma (2008) which paradigmatically stands for the contemporary preoccupation with the trauma phenomenon and which shall be later more closely analyzed. All these trauma narratives not only explore the aporetic attempt to represent the unrepresentable, but they also self-reflexively deal with cultural and theoretical discourses on trauma. In this way, literature fulfils the important role of giving an (indirect) voice to the unspeakable and repressed, thereby, implicitly constituting a theoretical text on trauma in the mode of fiction. Using the example of Patrick McGrath's novel Trauma, I will scrutinize the trauma phenomenon as thematic and aesthetic paradigm of contemporary literature. Against the backdrop of the aforementioned issues, special attention shall be given to the exact mechanisms of trauma's paradoxical structure of presence and absence, i.e. its call for articulation and simultaneous representational elusiveness. I will further ask which narrative techniques and stylistic devices the text employs to give (an aesthetic) voice to the unspeakable.

\section{McGrath's Trauma Narratives and the Concept of Trauma}

A son of a Medical Superintendent at England's famous Broadmoor Psychiatric Hospital, Patrick McGrath is renowned for the exploration of the uncanny realms of the unconscious and the subject's dark desires. Showing meticulous attention to psychological detail, his novels deal with deranged individuals who are haunted, for instance, by repressed homosexuality (The Grotesque, 1989) or the tragic effects of their traumatic childhood experiences (Spider, 1990). Whereas the issue of trauma is implicitly present in these texts, McGrath's recent novel, Trauma, makes this phenomenon explicitly subject matter in manifold ways.

Largely set in the New York of the 1970s and 1980s, Trauma centers on the first-person narrator Charlie Weir who works as a psychiatrist in Manhattan. The choice for his profession appears to be no surprise given his dysfunctional family 
background: when Charlie was eight years old, his father Fred, a drinker, left his mother. From then on, Charlie had to take care of his increasingly depressive mother, whereas his sheltered brother Walt was kept away from these problems. As Charlie retrospectively sums up his childhood, «[t]his is how psychiatrists are made» (McGrath, 2008: 7). As such, Charlie specialized in treating trauma patients, particularly Vietnam veterans. There he got to know his former wife Agnes, the sister of his patient Danny. After a - probably - too intense therapy session in a bar, Danny committed suicide. Overchallenged and guilt-ridden, Charlie thereupon left his wife together with their daughter Cassie instead of giving Agnes the support she was much in need of. After the death of Charlie's mother, about ten years later, he begins to make up with Agnes who meanwhile had remarried. He starts an affair with Agnes while still being in a relationship with Nora, a woman with a troublesome past. From then on, things start to fall apart: Charlie breaks up with Nora and wants to start afresh with Agnes. But even though she forgives him for the death of Danny, she can't forgive him having left her alone in those difficult times. Furthermore, Charlie loses his last backing as Walt and his family decide to move to Italy. Feeling completely left alone, Charlie increasingly shows signs of a major depression. He eventually decides to work at the Old Main, an Asylum which lies near the Western Hotel where he stayed a couple of days with his family as a child. The hotel, however, turns out to be a crucial place of Charlie's past. As his colleague Joan Bachinski suspects, Charlie himself is suffering a severe trauma - a suspicion that eventually gets confirmed by an unexpected visit of Walt and Fred: both reveal to him that this was precisely the place where he went into his parents' bedroom during a fierce quarrel between them. Thereupon, his mother pointed a gun at Charlie's head, shouting «This is what you get for going into other people's bedrooms, Charlie.» (McGrath, 2008: 206), and pulled the trigger. Fortunately, no shot was fired. Charlie recognizes that he had «forgotten» this episode and that he had displaced the traumatic experience onto his father whom he despised onwards. The novel concludes with Charlie eventually deciding to get psychological treatment.

The novel's surprising end has an enormous impact on Charlie's story as the latter demands a re-reading with respect to his traumatization: it raises the question whether Charlie's account is unreliable insofar as it is just a displaced narrative or a «screen» by which he articulates his unspeakable traumatic experience indirectly. Hence, the usual doctor-patient situation has to be reversed, i.e. we need to ask what Charlie's depiction of his patients actually reveals about his own pathology. But prior to this, the aforementioned paradoxical nature of 
the trauma phenomenon needs to be more closely elaborated. For this purpose, Charlie and his patients shall serve - in a first reading - as case studies.

Originally deriving from Greek $\tau \rho \alpha \hat{v} \mu \alpha$ 'wound', the term trauma was increasingly applied to psychological wounds since the late $19^{\text {th }}$ century, though it is still used in its original physical meaning in medical discourses nowadays (Luckhurst, 2008: 2f.). In the former sense, Sigmund Freud's works constitute the fundamental basis upon which a large number of succeeding trauma theories rest. ${ }^{2}$ In Beyond the Pleasure Principle, Freud identifies the source of a traumatic neurosis with a sudden «fright» that bursts through «the barrier against stimuli», i.e. an incident that exceeds the limits of the subject's individual coping abilities (Freud, 1920: 9-15, 29-32). To take the examples of Charlie and Danny: whereas the former was completely overwhelmed by the fact that it was his own mother who wanted to kill him («Unthinkable», McGrath, 2008: 206), Danny’s trauma is described as an overcharging «shock to the mind» (McGrath, 2008: 23). Furthermore, both not only suffer from exceeding experiences but particularly from the experience of having survived death («I [Danny] never expected to get home alive», McGrath, 2008: 126). As Cathy Caruth (1996: 58) argues in this regard, it is the «enigma of survival» which is paradoxically tied to trauma's destructiveness: «the trauma not only consists in having confronted death but in having survived, precisely, without knowing it» (Caruth, 1996: 64). That is, due to the exceeding shock of this unexpected fright the incident was never fully experienced nor processed, thus constituting a kind of mnemonic gap (Caruth, 1996: 58, 62, 64; also see Freud, 1914: 126ff.). Accordingly, Danny is not able to put his unperceived experience into a meaningful narrative ${ }^{3}$ and Charlie can only refer to it indirectly through mechanisms of displacement, such as in dreams or by replacing his mother with his father. Joseph Stein, one of Charlie's patients, has similar symptoms: accidentally having run over a pedestrian, Joseph both suffers from (a variant of) having survived death ${ }^{4}$ and needs Charlie's expertise to meaningfully transfer his trauma induced mnemonic gap into conscious memory.

However, these examples also show that the «unperceived» traumatic experience is not buried permanently in the depths of the unconscious since it hauntingly rises to the surface and prompts its articulation; the latter thus being in diametrical opposition to trauma's representational elusiveness. As Freud outlines in this regard, memory sets in belatedly (and indirectly) after the

2. For a comprehensive overview of the development of the trauma concept see the first part of Roger Luckhurst, The Trauma Question (2008).

3. «Certainly he [Danny] was haunted by repressed memories he hadn't yet found a means of articulating» (McGrath, 2008: 46).

4. «Having taken a life he didn't know why he should be allowed to live» (McGrath, 2008: 57). 
traumatization in the form of a repetition compulsion in which the traumatized (unconsciously) ${ }^{5}$ acts out his lost memory, thus rather repeating the traumatic event than consciously remembering it (Freud, 1914: 129-131). This acting out can manifest itself in dreams, flashbacks or hallucinations, as described in the illness of Post-Traumatic Stress Disorder (PTSD) by the American Psychiatric Association (Luckhurst, 2008: 1; Caruth, 1996: 57). Ideally, the patient «works through» his trauma by transferring it into conscious memory with the help of the psychoanalyst (Freud, 1914: 131-136). The characters of McGrath's novel show these symptoms in manifold ways: Danny is oftentimes «flashing back to the war» (McGrath, 2008: 43) and Nora is repeatedly haunted by nightmares in which her repressed traumatic experiences are indirectly acted out. Besides these distorted remembrances, the acting out of traumatic experiences can even assume the form of physical actions, as is the case with Charlie's patients Elaine Smith and Joseph Stein. Having been sexually abused by her father during childhood, Elaine acts out by proposing sex to patriarchal father figures, such as to her psychiatrist Charlie Weir, hence indirectly (and unconsciously) repeating her traumatic experiences. In the case of Joseph Stein, the physical acting out in the form of a suicide attempt indeed contributes to a successful working through of his trauma: after jumping from a building and becoming paraplegic, Joseph «absolved himself of the death of the pedestrian» (McGrath, 2008: 168) and is, from then on, no longer haunted by his former trauma. The delineated process of acting out, however, turns out to be deeply burdening as the trauma is experienced in each belated repetition for the first time - a psychological mechanism that Charlie equally suffers in his nightmares revolving around Danny's suicide: «It was the familiar horror, seeing the body as though for the first time. This is what trauma is. The event is always happening now, in the present, for the first time») (McGrath, 2008: 123).

It is precisely the concept of belatedness just described - i.e. «the missing of this experience, the fact that, not being experienced in time, it has not yet been fully known» (Caruth, 1996: 62) and its subsequent indirect repetition(s) - that makes the trauma inhabit a paradoxical status within the subject's psyche by being both known and unknown, present and absent. To take two examples regarding collective and individual traumas, when thinking about Danny and the other veterans, Charlie reflects about America's role in the Vietnam War:

5. «In some cases, Freud points out, these repetitions are particularly striking because they seem not to be initiated by the individual's own acts but rather appear as the possession of some people by a sort of fate, a series of painful events to which they are subjected, and which seem to be entirely outside their wish or control» (Caruth, 1996: 2). 
There were times when I regarded the pathology of the damaged men I worked with as emblematic of a far greater malaise, and I was apt then to be seduced by my own grand diabolical vision in which America played the part of a mad god eager to devour its young, the willing slave of its own death instinct [...] The irony was that fighting for your country rendered you unfit to be its citizen [...] (McGrath, 2008: 41f.)

Charlie intertextually alludes here to the antique myth of Kronos (Saturn), in which the latter devours his own children. ${ }^{6}$ Through the reference to this myth, Charlie tries to meaningfully articulate the unspeakable trauma(s) of the Vietnam War, especially the soldier's oftentimes unrecognized sacrifices. The myth thus fulfils the function of a soothing narrative that allegorically gives voice to the unspeakable, offering a model of explanation in view of the chaotic and senseless reality of war. In the case of Danny's individual trauma, reference is - similar to the previously illustrated examples - multiply displaced. After his traumatic Vietnam experiences, Danny's acting out manifested itself in acts of cannibalism, i.e. he ate dead people. This utterly strange behavior can be resolved when paying close attention to one of Danny's accounts:

«Four months, Charlie, until they shipped me out of there. I was an animal, I just wanted to kill. And I messed with their bodies if I could get at them. That's not an animal, that's worse than an animal. Animals don't kill because they like it.» «They kill to eat.» (McGrath, 2008: 134)

In the light of this passage, Danny's acting out turns out to be the result of a chain of displaced associations. Due to his terrible actions as a soldier he feels completely dehumanized, hence identifying himself with an animal. This identification, however, turns out to be problematic: whereas killing in wildlife is meaningful - i.e. animals hunt their prey in order to eat - (his) killing in war makes no sense to Danny. Consequently, his cannibalistic behavior is not only an acting out of his trauma but also his way to make sense out of his killing (i.e. by indeed acting like an animal and hence eating the dead).

As can be derived from these examples, trauma is fundamentally characterized by its «indirect relation to reference» (Caruth, 1996: 7), i.e. it is a mnemonic void in which the (alleged) unity of signifier and signified is deeply disrupted. If at all possible, it can only be represented or, to be more precise, approximated through representational supplements (e.g. displaced narratives/actions or with the help of universal models of explanation such as myths). In either case, however, these supplements ultimately fail to bridge the gap between the traumatic experience and its articulation, between signified and its lost signifier. As a

6. Kronos fears that his children will revolt against him (just as he did with his father Uranus). 
consequence, the traumatized compulsively repeats the traumatic event, vainly attempting to represent and hereby grasp its exceeding totality. A manifestation of the Freudian death drive, this compulsive repetition of the destructive event via displaced permutations can eventually culminate in annihilation (Caruth, 1996: 62f.) as Danny's suicide, Joseph Stein's failed suicide and the following analysis of Charlie's (self-)destructive tendencies further suggest.

\section{The Presence of Charlie's Trauma(s) within Representational Absence}

Although Charlie narrates from a predominantly objective and medical perspective, thereby oftentimes rationally analyzing his own behavior, he largely fails to recognize his deep-seated childhood traumatization. That is, his actions

and, particularly, his act of narration are indirect repetitions (respectively acting outs) of his trauma - a situation that Charlie is only roughly conjecturing, let alone grasping in its severe implications: «My patients were my distraction, my solace, my sanity, and to them I clung» (McGrath, 2008: 168). In this regard, the unexpected revelation at the novel's end throws a new light upon Charlie's narrative, for the bedroom episode not only constitutes the source of his traumatization but it is also acted out in manifold ways. His mother's accusation of «going into other people's bedrooms» (McGrath, 2008: 206) and «always interfering» (McGrath, 2008: 143) turns out to be the real underlying reason for the choice of his profession: as a psychiatrist, Charlie is - figuratively speaking - indeed going into other people's bedrooms, i.e. he intrudes his patients' private spaces by digging into their repressed memories. As a consequence, Charlie's profession is an ongoing acting out via treating patients. Thereby, the patients' traumas are densely interwoven with Charlie's own childhood trauma, all of them mirroring partial aspects of the latter.

This can be seen, first and foremost, in his specialization in treating Vietnam veterans as this kind of work frequently involves traumatic experiences with firearms, the latter thus indirectly referring to the gun that his mother pointed at him. In the case of Danny, however, Charlie's acting out leads to unforeseen consequences. After being pushed too hard by Charlie - who is again interferring and thus repeating his own trauma indirectly - Danny commits suicide by shooting himself in the head. Charlie appears to be immediately traumatized and feels guilty for Danny's death:

I had to look at the mess he'd made of his head. It did more than haunt me, it became yoked in my psyche to the guilt I felt. And the memory did not fade or change; it returned with all the immediacy and specificity of the experience itself, usually in my dreams. (McGrath, 2008: 144) 
Yet, Charlie's self-analysis has to be treated with caution. In the light of the novel's end and Joan Bachinski's suspicion, ${ }^{7}$ his (seemingly) traumatic obsession with Danny's death proves to be just a displacement or screen: Charlie's nightmares revolving around Danny's death as well as the very suicide itself are, in fact, variations of his former nightmares. In those he dreamed of his father pointing a gun at his head, which is itself a displaced version of his childhood trauma. We can see then that Charlie is not traumatized by Danny's suicide, but the latter rather triggers his original trauma, which is subsequently repeated in deferred nightmares of Danny. The aforesaid is, moreover, closely interrelated with the case of Joseph Stein, which is equally multiply displaced: by treating Stein, who likewise killed a person accidentally, Charlie tries to cope with his guilt with regard to Danny. Stein's failed suicide, however, triggers Danny's («It was the word suicide. I saw Danny sprawled on the floor of his apartment, with a gun on the floor beside him», McGrath, 2008: 170), which in turn refers to Charlie's childhood trauma. Hence, Charlie's treatment of Stein is an additional attempt to understand his own trauma that is buried in the deep structure of Danny's case. The described indirect repetitions of Charlie's traumatic gun experience eventually culminate by the novel's end. After the revelation of the real incidents at the Western Hotel, Charlie gets into a fight with his brother Walt, during which he shoots at the latter with the same gun that his mother had used before. Interestingly, Charlie is not completely conscious about his actions, «The childhood nightmare came back to me then [...] I don't recall picking the gun up out of the snow» (McGrath, 2008: 208), which underlines trauma's compulsive and (oftentimes) unconscious pattern of repetition. The last iteration of his trauma takes place shortly after the episode just mentioned: Charlie desperately thinks about committing suicide just as Danny did («Our situations were identical [...] I shifted around until I was in the exact position Danny had been when I found him [...] I wanted to do it right, like Danny», McGrath, 2008: 209), though he rejects this thought in view of his daughter Cassie. In the light of Charlie's series of increasingly painful acting outs, it is especially this almost suicide which finally exposes the (self-)destructive tendencies of the compulsion to repeat the trauma.

Taken together, these examples illustrate trauma's complex structure of deferred repetition: starting with the projection of his own trauma onto his patients right through to multiply displaced nightmares, Charlie's various acting outs eventually reach their climax in his almost suicide after the wounding of

7. «the real trauma lies elsewhere. It might be very deep. And I [Joan Bachinski] think Danny's just a screen» (McGrath, 2008: 197). 
Walt. Though being different situations in different contexts, they are all bound together by their indirect structure of relation. That is to say, they all inevitably point to Charlie's initial trauma via the previously described mechanisms of displacement and/or association, thus ultimately testifying trauma's paradoxical presence within representational absence.

Besides the aforementioned examples, which primarily revolve around the issue of the gun, further aspects of Charlie's childhood trauma can be discerned. These equally follow a repetitive pattern that comprises the motive of «being left alone» and Charlie's problematic relationship with women. With regard to the former we need to take up again his initial trauma: the experience of being mock executed by one's own mother is - especially in the phase of early childhood - a severe disruption of the crucial mother-son relationship. As a consequence, intense feelings of traumatic abandonment arouse - a breach that young Charlie could not face with regard to his mother whom he onwards replaced by his father: «Unthinkable, that my mother could do that to me. The unconscious wouldn't sanction it for a moment. So it got displaced onto Fred» (McGrath, 2008: 206). This partly elucidates why Charlie's condition is deteriorating over the years for his trauma is triggered each time he is left alone. The most decisive instance in this respect is the recent death of his mother:

It was accompanied by what I can only call a wave of purest blackness. I recognized it as the sort of precipitate mental collapse that had characterized by mother's depression, and I felt [...] that I'd become infected with her illness. I saw it then, Mom's depression, as a parasite deprived of its host and finding me instead. (McGrath, 2008: 18)

Again, Charlie is misconstruing his situation since the «wave of purest blackness» also alludes to the traumatic and therefore unrepresentable childhood experience where his mother had abandoned him for the first time. Through her death - a displaced variant of «being left alone» - he is, in fact, reliving a crucial aspect of his initial trauma. However, since Charlie had suppressed the latter, thereby unconsciously replacing his mother with his father, he could not be completely aware of the true nature of his alleged «depression». Moreover, the fact that his father left the family when Charlie was a child not only triggered parts of his trauma already back then - i.e. the father as a substitute for the mother failed Charlie anew - but it further kindled his hatred towards him. This behavior pattern is repeated in two more instances: whereas Joseph Stein's recovery 
provokes the contrary effect in $\mathrm{Charlie}^{8}$ as he is about to lose his soothing patient into whom he projected his own trauma, he completely overreacts when Walt tells him about his plans to move with his family to Italy. ${ }^{9}$ In both cases it is the experience of being abandoned which indirectly refers to Charlie's initial trauma and decisively adds to his ongoing decline.

The picture gets eventually completed when taking into account Charlie's ambivalent relationship with women. In this regard, we need to take a closer look at his (ex-)partners Agnes and Nora, who both take the role of a mother figure:

At times Agnes went into the bedroom after he'd [Danny] gone and closed the door behind her, and I could hear her crying in there. It reminded me of my mother, of course, and as with her I would go to Agnes and give what comfort I could. (McGrath, 2008: 43)

Nora reminded me strongly of my mother. (McGrath, 2008: 76)

It had become clear to me that this obsession I had with the idea of home-the pursuit of Agnes, a woman who didn't want me, and this bizarre compulsion to re-create my mother's bedroom, as though trying to return to the womb-was nothing more than an urge to repeat the past. (McGrath, 2008: 189)

What Charlie is not completely aware of is that he is, in fact, trying to get at the point before his trauma, i.e. at the point when the traumatic separation from his mother had not yet taken place. Through his (sexual) relationships with Agnes and Nora he tries to re-create the former intact mother-son relationship and thus to regain his lost object of desire. This even leads to the point that he has sex with Nora in his mother's bed, which constitutes a multiply deferred acting out of his compulsion to return to the most possible pre-traumatic state, i.e. «to return to the womb» (McGrath, 2008: 189). In this (almost) incestuous context, Charlie's treatment of Elaine - whose father «started coming to her bedroom at night» (McGrath, 2008: 183) - may further be a displaced redoubling of his own trauma. Moreover, Charlie's acting out even assumes the complete opposite form as it is him who later abandons Nora and Agnes, hence indirectly repeating the experience of being left alone. With respect to Agnes, Charlie is again

8. «His mental health grew more robust each time I saw him, and mine decayed» (McGrath, 2008: 171).

9. «Later, it occurred to me that my anger had nothing to do with the furniture. It was about Walt and his family going away for a year. I'd simply displaced the anger, unwilling to acknowledge how much I resented being abandoned» (McGrath, 2008: 74). Again, Charlie is an unreliable narrator insofar as he fails to relate his resentment to «being abandoned» to his own traumatization, hence misdiagnosing himself. 
misdiagnosing himself: "It later occurred to me that by failing Agnes I had again failed my mother. I'd behaved exactly as Fred had» (McGrath, 2008: 149). For in the light of the previously outlined mechanisms of displacement it becomes clear that his father Fred is just a substitute and that Charlie is therefore rather repeating his mother's actions.

The foregoing discussion has shown that the acting out of a trauma can assume highly different forms which, however, never succeed in fully re-creating the original experience. It is precisely this simultaneous presencelabsence which, in turn, constitutes the origin of trauma's repetition compulsion as the traumatized is vainly (and thus continuously) attempting to fully represent his lost memory. This paradoxical structure of the trauma makes Charlie a highly unreliable narrator insofar as his precarious mental state affects his narrative already from the novel's beginning on. A reversal of the traditional hierarchy, Charlie's depiction of his patients reveals, in fact, more about his own pathology than about that of his patients: his apparent objective and medical discourse is itself pathological to a high degree as it is the manifestation of an ongoing acting out. Nevertheless, the previous analyses have demonstrated that we can, at least, adumbrate the true nature of Charlie's trauma by reading «between the lines» of his unreliable narration, thus grasping trauma's presence within representational elusiveness.

\section{Traumatic Spaces}

As has been pointed out, Charlie's unreliable narration testifies to his highly fragmented inner condition that eventually leads to his decay. This movement from order to chaos is also reflected in the novel's spatial configuration, which becomes an important carrier of meaning: we should not forget that Charlie is narrating from a highly subjective perspective, i.e. the spaces depicted are closely interrelated with his mental condition as they are also his (un)conscious projections. As a consequence, Charlie's movement through different places and spaces describes at the same time a movement back in time, ultimately leading to the origin of his trauma.

At the time he begins narrating the events of his life, Charlie lives in an apartment at West twenty-third Street in Manhattan. In analogy to his, at first, well-ordered narrative, his apartment appears to be a harmonious, open space ${ }^{10}$

10. «a good-sized two-bedroom with a view of the river»; «a broad arched opening» (McGrath, 2008: 31). 
where he not only finds distraction but where he can also retreat to work. ${ }^{11}$ However, the depiction of his apartment already shows signs of its decay as can be seen by the slight reference to its view «all the way down to the twin towers» (McGrath, 2008: 31) - an allusion that reappears several times as a leitmotif in the course of the novel (McGrath, 2008: 12, 31, 90, 173). With the help of these references, McGrath is playing with the reader's historical horizon of experience: by the time of the novel's publication in 2008, the World Trade Center's collapsed twin towers already constituted an important memorial site with regard to the collective trauma of the 9/11 terrorist attacks. By means of this reference McGrath is creating the uncanny atmosphere of an approaching catastrophe, if not triggering the reader's own traumatic memory of the incident. In the context of the novel itself, moreover, the twin towers become a powerful symbol for Charlie's rising trauma and his approaching collapse: while still under construction at the novel's very beginning (McGrath, 2008: 12), Charlie's description of the twin towers changes from rather neutral (McGrath, 2008: 31) to the image of «cliffs of blackness» (McGrath, 2008: 90). The latter symbolizes his trauma induced mnemonic gap which is, paradoxically, becoming more and more present in his life. This image is eventually completed in the novel's fifteenth chapter, when Charlie realizes that things start to fall apart («It is from this night that I date my decline», McGrath, 2008: 167). Once again, he is looking out of his window:

[t]o the south the twin towers, to the west [...] the emptiness of the sky over the river. I rattled the railing and heard the rusted rivets creak as they shifted about in their housings. It wasn't difficult to imagine the whole thing coming loose, and me stepping into space. (McGrath, 2008: 173)

In this highly figurative passage, «the emptiness of the sky» not only alludes to his traumatic void anew but it is additionally linked with his mentally unstable condition as the loose, rusty railing metaphorically suggests. In the following last third of the novel Charlie finally confronts his real trauma, thus approximating the representational emptiness of his lost memory or, according to him, «stepping into space».

A decisive step towards his trauma's origin is the return to the apartment at Eighty-seventh Street, where he spent his childhood. Shortly after his brother Walt moved out, Charlie undoes the latter's renovations so that his mother's former bedroom becomes «a monument to the past, a shrine to the presence that

11. «[t]wo walls were given over to bookshelves»; «[t]here was a good stereo system and some framed reproductions of works by surrealists»; «the dining table was always heaped high with papers and journals» (McGrath, 2008: 31). 
still imbued it» (McGrath, 2008: 181). What Charlie is doing here is, in fact, a spatial acting out: by meticulously reconstructing his mother's bedroom he is, unconsciously, trying to lay open his repressed traumatic memory. He partly succeeds in this task for he indeed feels «the presence of repressed memory-the memory of a catastrophic event» (McGrath, 2008: 182). As we know from the novel's end, however, this is just a deferred memory as this particular bedroom metonymically refers to the bedroom of the Western Hotel, the primal scene of his trauma. In the light of the fact that Charlie still has not succeeded in fully articulating his lost memory, he finally decides to move to Catskill and work at the Old Main Asylum which lies near the said Western Hotel. We can see then that almost all of Charlie's decisions and actions are results of trauma's repetition compulsion, manifesting themselves in various, highly displaced acting outs. Although being partly aware of his compulsive behavior («I felt that somehow I'd been intended for the Old Main», McGrath, 2008: 192), Charlie still doesn't realize why he is walking to the Western Hotel every day (McGrath, 2008: 195). It is not until Walt's subsequent revelation that he comprehends the true origin of his traumatization. This epiphanic realization is redoubled in the episode's spatial configuration: the more Charlie is approaching his traumatic memory, the darker it gets («It was growing dark outside») and the harder it snows (McGrath, 2008: 204, 207). These - predominantly colorless - images of night, storm and snow symbolically evoke the notion of a spatial void which, in turn, mirrors Charlie's travel back in time towards his mnemonic gap. After having confronted his traumatic past and having rejected his suicidal intent, Charlie finally decides to get psychological treatment - a moment of lucidity that is again reflected by the novel's representation of space: the snowfall ceases and Charlie notices «[t] he first lights touching the turrets of Old Main» (McGrath, 2008: 210).

\section{Conclusion: Towards an Aesthetics of the Unrepresentable}

Through the example of Patrick McGrath's Trauma, the present study has shown literature's capabilities to reflect trauma's paradoxical (un)representability. Based on the results of the previous analyses, the following main aesthetic techniques, with which literary texts are able to give a narrative voice to the unspeakable, can be abstracted.

The device of an unreliable narrator (1): as has been argued, Charlie's utterances receive additional meanings which hint at the underlying, yet unrepresentable trauma. A reversal of the Cartesian cogito, it is particularly the unconscious realm of the trauma which highly influences the subject's being, i.e. by decisively determining its development and its actions. These complex psychological mechanisms can be effectively brought to light with the help of 
unreliable narration's twofold structure. Repetitions with differences (2): the repeated use of elements on both narrative levels of story and discourse - such as recurring plot elements, certain themes/leitmotifs or verbal habits - can visualize trauma's repetition compulsion which, in turn, is an effect of its representational elusiveness. Intertextuality (3) as a means to indirectly represent the inaccessible: intertexts (e.g. Charlie's recourse to the myth of Kronos with regard to the Vietnam veterans) can function as schemes of knowledge with which unspeakable, traumatic experiences are (partially) articulated, thereby reducing the complexity of trauma's exceeding singularity. The semantics of space (4): especially in the case of I-narrators, the opposition between inside and outside is suspended for there can be stated a close relation between the subject's mental condition and its spatial perception. As has been exemplified by Charlie's depiction of spaces, his (unconscious) movement towards the original place of his traumatization concurs with an increasing spatial void, most notably symbolized by images of snow and darkness. An analysis of the spaces depicted together with their symbolic, metaphoric or metonymic - relation to the actual plot can additionally shed light on unperceived details of the narrator's/character's trauma.

With that said, McGrath's novel can be further read as a metareflection on theoretical trauma discourses. Not only does it incorporate classical trauma theories and exemplify them with the aid of its various characters, but Charlie's unreliable narration is also a warning manifestation of the problem of transference between doctor and patient: fundamentally arising from trauma's representational crisis, Charlie's acting out via treating patients defines the limits of psychoanalytical therapy by raising the question to which extent the analyst may be unconsciously projecting his own, deep rooted trauma(s) into his patient(s).

\section{Works Cited}

Caruth, C. (1995): «Recapturing the Past: Introduction» in Caruth, C.; G. Bataille (eds.) (1995): Trauma: Explorations in Memory, Baltimore, Johns Hopkins UP. 151-156.

- (1996): Unclaimed Experience: Trauma, Narrative, and History, Baltimore, Johns Hopkins UP.

FreUd, S. (1914): «Erinnern, Wiederholen und Durcharbeiten» in FreUd, A. (ed.) (1967): Gesammelte Werke: Bd. 10, Frankfurt a. M., Fischer. 126-136.

- (1920): «Jenseits des Lustprinzips» in FREUD, A. (ed.) (1967): Gesammelte Werke: Bd. 13, Frankfurt a. M., Fischer. 3-69.

LuCKHURST, R. (2008): The Trauma Question, London, Routledge.

LyotARD, J.-F. (1994): La condition postmoderne: rapport sur le savoir, Paris, Éd. de Minuit. 
MCGRATh, P. (2009): Trauma, London, Bloomsbury.

Roth, M. S. (2011): Memory, Trauma, and History: Essays on Living with the Past, New York, Columbia University Press. 